\title{
Gold-Catalyzed C-H Bond Functionalization of Metallocenes: Synthesis of Densely Functionalized Ferrocene Derivatives
}

\author{
Enol López, Giacomo Lonzi and Luis A. López* \\ Instituto Universitario de Química Organometálica "Enrique Moles” and Departamento de Química Orgánica e Inorgánica, \\ Universidad de Oviedo, c/ Julián Clavería 8, 33006-Oviedo, Spain,
}

Supporting Information Placeholder

\begin{abstract}
A convenient process for the direct functionalization of ferrocene that exploits the high electrophilic character of gold-vinyl carbenoids catalytically generated from vinyldiazo compounds and gold complexes is reported. This process takes place with complete regioselectivity (vinilogous reactivity). The synthesis of the corresponding ruthenocene analogues has also been achieved. Preliminary studies on the reactivity of these new organometallic compounds seems to suggest that the presence of the adjacent ferrocenyl group confers a specific reactivity on the functionalized carbon chain manifested in the easy dry state aerobic allylic oxidation.
\end{abstract}

More than sixty years after the discovery of ferrocene, ${ }^{1}$ the chemistry of this organometallic compound continues to captivate chemists. This interest is based, mainly, on the huge number of applications of functionalized ferrocenes in several relevant areas including catalysis, material science and medicine. ${ }^{2}$ Accordingly, the development of new and efficient methods for the synthesis of functionalized ferrocenes is highly desirable.

In contrast to the situation found in other metallocenes, direct functionalization of the ferrocene is viable since its robust nature makes it compatible with the reaction conditions required for most common organic transformations. However, despite recent advances, ${ }^{3}$ the number of currently available methodologies for the direct attachment of carbon chains bearing functional groups to the ferrocene remain very limited and can be classified into two general categories: a) initial Friedel-Crafts acylation followed by subsequent transformations of the resulting acylferrocene, ${ }^{4}$ and b) initial formation of ferrocenyl lithium by treatment with alkyllithium reagents followed by coupling with a suitable carboelectrophile. ${ }^{5}$ These classical methodologies have been successfully applied to the synthesis of many functionalized ferrocenes; however, these approaches also entail some limitations. Thus, in general, a multistep sequence is often required to install specific functionalities in remote positions. Moreover, these methodologies display a low functional group compatibility (particularly the second one, due to the high reactivity of ferrocenyl lithium).

As expected, in general, Friedel-Crafts alkylation reactions of ferrocene do not represent a convenient synthetic method because mixtures of several alkylation products are formed. ${ }^{6}$

On the other hand, the generation of electrophilic carbene species via transition-metal-catalyzed decomposition of $\alpha$-diazo carbonyl derivatives and their subsequent reactivity in addition and insertion reactions has become a powerful methodology in organic synthesis. ${ }^{7}$ Surprisingly, in spite of the tremendous impact of gold catalysis in synthetic organic chemistry, ${ }^{8}$ the use of gold complexes for the catalytic decomposition of $\alpha$-diazo carbonyl derivatives has been unexplored until recently. Indeed, in 2005 Nolan, Díaz-Requejo, Pérez et al reported the first gold-catalyzed decomposition of ethyl diazoacetate and the subsequent reactivity of the resulting carbenic species in addition and insertion reactions. ${ }^{9}$ After this seminal contribution, this field has evolved very rapidly with more and more gold-catalyzed transformations of simple diazo compounds. ${ }^{10}$ In sharp contrast, the gold-catalyzed transformations involving vinyldiazo derivatives remain less studied. ${ }^{11}$ In this regard, we recently reported the gold-catalyzed coupling of vinyldiazo derivatives and unsaturated substrates. ${ }^{12}$ The reaction is believed to proceed by means of a gold-vinyl carbenoid intermediate with a high electrophilic character at the terminal position. ${ }^{13,14}$ Particularly, we found that a number of activated arenes were able to react with vinyldiazo compounds affording the corresponding $\mathrm{C} \gamma$-arylation products (Eq. 1). ${ }^{12 \mathrm{a}}$

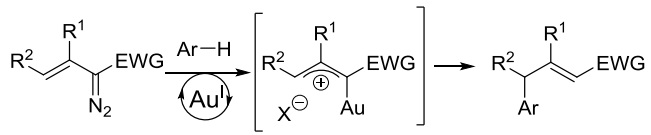

On the basis of these findings, we questioned whether the use of ferrocene would lead to an analogous coupling, providing functionalized ferrocene derivatives. Herein, we disclose the successful realization of this purpose and report a simple goldcatalyzed protocol for the preparation of ferrocene (and ruthenocene) derivatives bearing a functionalized allyl group. This method represents an unusual example of functionalization of metallocenes involving carbenes as reaction partners. ${ }^{15}$ Preliminary studies on the reactivity of the new functionalized ferrocene derivatives prepared are also reported.

In accordance with our previous research, $\left[\mathrm{Au}(\mathrm{IPr})\left(\mathrm{CH}_{3} \mathrm{CN}\right)\right] \mathrm{SbF}_{6}$ in dichloromethane was initially selected as the catalytic system. Thus, stirring a solution of vinyldiazoacetate $\mathbf{1 a}\left(\mathrm{R}^{1}=\mathrm{R}^{2}=\mathrm{H}\right)$, ferrocene (2a, 4 equiv), and $\left[\mathrm{Au}(\mathrm{IPr})\left(\mathrm{CH}_{3} \mathrm{CN}\right)\right] \mathrm{SbF}_{6}(5 \mathrm{~mol} \%)$ in dichloromethane at room temperature for $4 \mathrm{~h}$ resulted in the isolation of ethyl $(E)-4-$ ferrocenylbut-2-enoate (3a) as a yellowish oil in $75 \%$ after chromatographic purification (Scheme 1). ${ }^{16}$

This gold-catalyzed reaction entails some significant features: 1) It takes place with complete regioselectivity being only the vinilogous position of the vinyldiazoacetate involved, ${ }^{14}$ 2) exclusive formation of the $E$-isomer was observed, and 3) although allylsubstituted ferrocenes are known, ${ }^{17}$ compound 3a bearing a ethoxycarbonyl group bound to the allyl moiety is a new and densely functionalized ferrocene derivative of potential interest. 
Further studies performed to determine the scope of this goldcatalyzed process are provided in Scheme 1. First, we observed that the nature of the ester group does not affect notably the course of the reaction. Indeed, tert-butyl- $\left(\mathbf{1 b} ; \mathrm{R}^{1}=\mathrm{H}, \mathrm{R}^{2}=\mathrm{H}\right.$, EWG $\left.=\mathrm{COO}^{t} \mathrm{Bu}\right)$, and benzylsubstituted $\left(\mathbf{1} \mathbf{c} ; \mathrm{R}^{1}=\mathrm{H}, \mathrm{R}^{2}=\mathrm{H}\right.$, EWG $=$ COOBn) vinyldiazo compounds undergo the coupling process affording the functionalized ferrocene derivatives $\mathbf{3 b}$ and $3 \mathbf{c}$ in moderate yields as single $E$ estereoisomers. The reaction scope was then extended to vinyldiazo compounds substituted at the vinyl moiety. In this regard, we observed that an alkyl group at the $\mathrm{C} \alpha$ atom (diazoacetate $1 \mathbf{d} ; \mathrm{R}^{1}=\mathrm{Me}, \mathrm{R}^{2}=\mathrm{H}, \mathrm{EWG}=$ COOEt) could be utilized to produce the ferrocene derivative $\mathbf{3 d}$. In contrast to the previous examples involving unsubstituted diazocompounds 1a-c, in this case the product was obtained as a mixture of $E(42 \%)$ and $Z(21 \%)$ isomers, each easily separable by flash chromatography. In agreement with previous observations, we found that substitution at the $C \beta$ position has a detrimental effect on the coupling reaction. In fact, $\beta$-substituted diazoacetate 1e $\left(\mathrm{R}^{1}=\mathrm{H}, \mathrm{R}^{2}=\mathrm{Et}, \mathrm{EWG}=\mathrm{COOEt}\right)$ afforded the corresponding ferrocene derivative $3 \mathbf{e}$ in low yield $(12 \%)$ after heating in DCE at $50^{\circ} \mathrm{C}$ for $10 \mathrm{~h}$. Interestingly, compound $3 \mathbf{e}$ was isolated as a single $E$ isomer. Pleasingly, we found that diazo derivatives bearing other stabilizing groups can also participate in this coupling. For instance, vinyldiazo compound $\mathbf{1 f}\left(\mathrm{R}^{1}=\mathrm{Me}, \mathrm{R}^{2}=\mathrm{H}\right.$, EWG = $\mathrm{COMe}$ ) featuring an acetyl group gave ferrocene derivative $\mathbf{3 f}$ in $50 \%$ yield and predominantly as the $E$ isomer ( $E / Z 14: 1$ according to the ${ }^{1} \mathrm{H}-\mathrm{NMR}$ of the crude reaction).

Scheme 1. Gold-catalyzed reaction of alkenyl diazo derivatives 1 and ferrocene $(2 a)^{a}{ }^{a}$

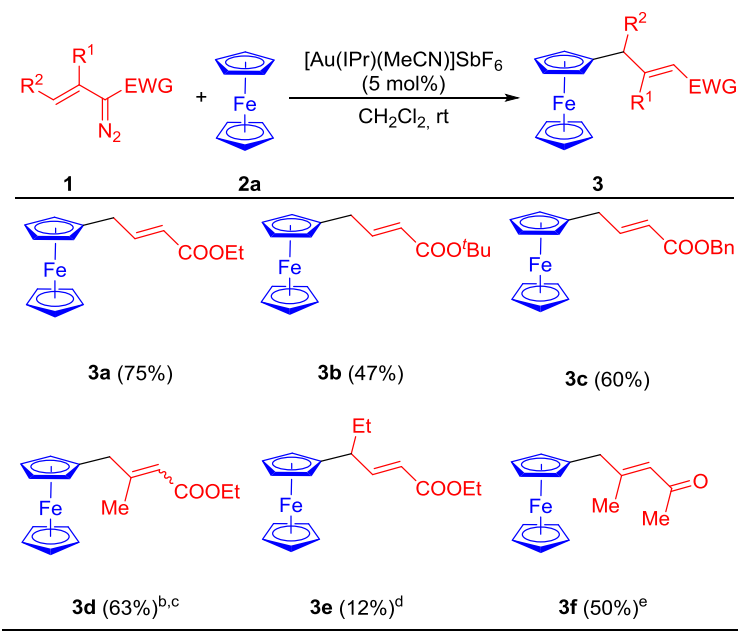

${ }^{\mathrm{a}}$ Reaction conditions: $\mathbf{1}(0.5 \mathrm{mmol}), \quad \mathbf{2 a} \quad\left(\begin{array}{lll}2.0 & \mathrm{mmol}\end{array}\right)$, $\left[\mathrm{Au}(\mathrm{IPr})\left(\mathrm{CH}_{3} \mathrm{CN}\right)\right] \mathrm{SbF}_{6}(5 \mathrm{~mol} \%), \mathrm{CH}_{2} \mathrm{Cl}_{2}(0.1 \mathrm{M})$, rt. Values within parentheses represent yields of the isolated products after column chromatography. ${ }^{\mathrm{b}} \mathrm{A}$ separable mixture of $E(42 \%)$ and $Z$ $(21 \%)$ isomers was obtained. ' Reaction conducted in 1,2dichloroethane. ${ }^{\mathrm{d}}$ Reaction conducted in 1,2-dichloroethane at 50 ${ }^{\circ} \mathrm{C}$. ${ }^{\mathrm{e}} \mathrm{A} 14: 1$ mixture of $E / Z$ isomers was obtained.

The regio- and stereochemistry of compounds 3a-f were ascertained by NMR experiments. Moreover, an X-ray analysis was performed on compound $(E)$-3f (Figure 1).

Next, we conducted some experiments aimed at obtaining information about the mechanism of this transformation. First, the reaction of vinyldiazo compound $\mathbf{1 a}$ with deuterated ferrocene under the standard conditions resulted in the formation of the corresponding ferrocene derivative with incorporation of deuterium at the $\alpha$-position (Eq. 2). The effect of the electronic properties of the ferrocene component on the rate of the coupling reaction was also investigated. Indeed, a competition experiment between ferrocene (2a) and acetylferrocene $(\mathbf{2 b})$ resulted in the exclusive formation of compound 3a (Eq. 3). Finally, in good agreement with the above-mentioned competition experiment, we observed that the reaction of vinyldiazo compound $\mathbf{1 a}$ and acetylferrocene (2b) resulted extremely sluggish. In this regard, we found that prolonged heating ( $>24 \mathrm{~h}$ ) a solution of $\mathbf{1 a}, \mathbf{2 b}$ and the gold catalyst $(5 \mathrm{~mol} \%)$ in 1,2-dichloroethane at $50{ }^{\circ} \mathrm{C}$ afforded disubstituted ferrocene derivative $\mathbf{3 g}$ (Eq. 4). Interestingly, although compound $\mathbf{3 g}$ is formed in very low yield, the incorporation of the functionalized allylic moiety took place exclusively at the unsubstituted cyclopentadienyl ligand.

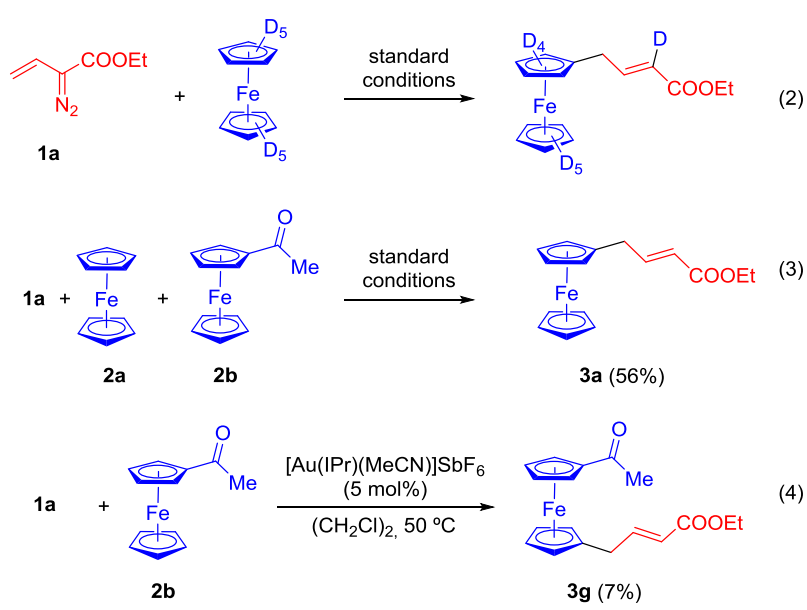

These experimental mechanistic data are consistent with an electrophilic aromatic substitution pathway (Scheme 2). ${ }^{18}$ Thus, in accordance with previous work, ${ }^{11,12}$ the process would be initiated with the formation of a gold alkenyl carbenoid intermediate $\mathbf{I}$, which would act as the electrophillic partner in an electrophilic aromatic substitution to give, after reaction with ferrocene, the $\sigma$ complex intermediate II. Subsequent deprotonation and protodemetalation would account for the formation of the final functionalized ferrocene derivatives 3 .

Scheme 2. Proposed mechanism for the Au(I)-catalyzed synthesis of functionalized ferrocene derivatives 3 .

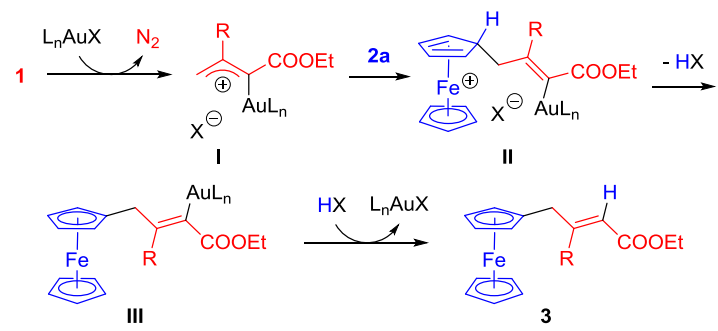

Next, we decided to extend this gold-catalyzed reaction to ruthenocene. In this regard, we found that the reaction required more vigorous conditions than those needed for the preparation of the ferrocene analogues. This fact is fully consistent with our mechanistic proposal because the lower reactivity of ruthenocene toward electrophilic aromatic substitution reactions is welldocumented. ${ }^{19}$ Thus, heating for $12 \mathrm{~h}$ a solution of vinyldiazo compound 1a, an slight excess of ruthenocene (4) and 
[Au(IPr) $\left.\left(\mathrm{CH}_{3} \mathrm{CN}\right)\right] \mathrm{SbF}_{6}(5 \mathrm{~mol} \%)$ in 1,2-dichloroethane at $50{ }^{\circ} \mathrm{C}$ afforded the corresponding functionalized ruthenocene derivative $\mathbf{5 a}$ in $25 \%$ yield after chromatographic purification (Eq. 5). ${ }^{20}$ In a similar way, vinyldiazo compound $\mathbf{1 b}$ reacted with ruthenocene giving rise to the metallocene $\mathbf{5 b}$ in moderate yield. As in the case of the ferrocene analogues, the formation of compounds $\mathbf{5 a}, \mathbf{b}$ took place with total regio- and $(E)$-stereoselectivity. The structure of $\mathbf{5 b}$ has been determined by an X-ray crystal analysis after crystallization from pentane (Figure 1).
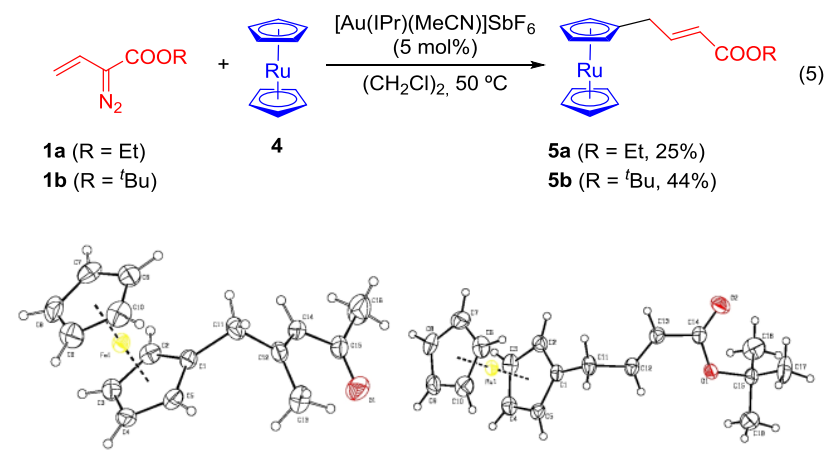

Figure 1. X-ray structures of $(E)$-3f (left) and $(E)$-5b (right). Thermal ellipsoids are drawn at the $30 \%$ probability level.

When investigating the scope of the gold-catalyzed reaction of vinyldiazo compounds $\mathbf{1}$ and ferrocene (2), we observed that in some cases along with the corresponding ferrocene derivative $\mathbf{3}$ small amounts of a side product were also isolated after the chromatographic purification. For example, a violet fraction corresponding to a more polar compound was collected in the chromatographic purification of ferrocene derivative 3a. This side product was identified as ethyl $(E)$-4-ferrocenyl-4-oxoprop-2-enoate (6a) demonstrating that an oxidation of the methylene group bound to the ferrocenyl moiety took place. ${ }^{21}$ Given that the ${ }^{1} \mathrm{H}$ NMR of the reaction crude did not reveal the presence of this compound we wondered about its formation. In this regard, we observed an immediate change in colour (from orange to violet) when samples of pure ferrocene $\mathbf{3 a}$ adsorbed on silica gel in vacuum were exposed to air. Compound $\mathbf{6 a}$ was obtained in this way in moderate yield (25-30\%). Further studies demonstrated that the oxidation process of compound 3a was more efficient when 1 atm of oxygen was used instead of air; in this way reproducible yields about $50 \%$ could be obtained (Eq. 6). Control experiments showed that both oxygen and silica gel are required for the oxidation. In particular, the adsorption on silica gel seems to play a decisive role in this aerobic oxidation process. ${ }^{22}$ Similarly, ferrocene derivatives $\mathbf{3 b}, \mathbf{c}$ were converted in the corresponding oxo-substituted derivatives $\mathbf{6 b}, \mathbf{c}$ (Eq. 6). In spite of the modest yields, the transformation of ferrocene derivatives 3a-c into compounds 6a-c represents an unusual oxidation of an allylic position under aerobic conditions. ${ }^{23,24}$

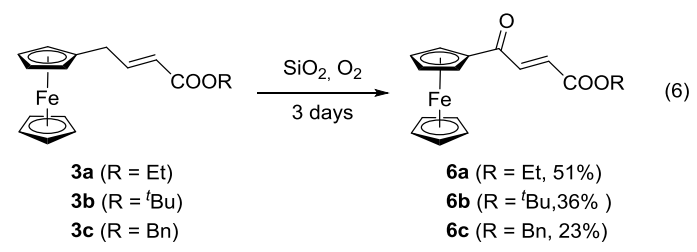

Finally, owing to our interest in the chemistry of vinyldiazo compounds we explored the feasibility of transforming compounds 3 into new vinyldiazo compounds bearing a ferrocenyl group. For our exploratory study, we investigated the reaction of ferrocene derivative 3a and 4-acetamidobenzenosulfonyl azide ( $p$ ABSA) as the diazo transfer reagent in acetonitrile at $0{ }^{\circ} \mathrm{C}$ (Eq. 7). After conventional work-up and chromatographic purification we were able to isolate 2-diazo-4-ferrocenylbut-3-enoate (7a) as a orange oil in a synthetically useful yield $(62 \%)$. Taking into account the rich chemistry that has been reported in the last years for vinyldiazo derivatives, compound 7a can be envisioned as a realistic starting reagent for the synthesis of a wide range of new functionalized ferrocene derivatives by means of well-established experimental protocols. ${ }^{25}$

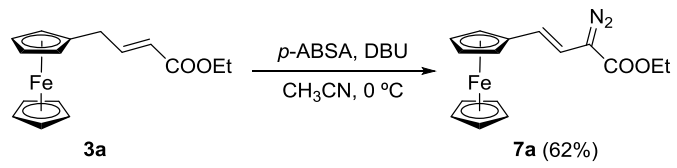

In conclusion, we have developed a formal gold-catalyzed C-H functionalization of ferrocene and ruthenocene through a electrophillic substitution reaction. The reported process represents a new application of vinyldiazo compounds in gold catalysis, a young yet promising research topic. This process enables the preparation of metallocene derivatives with an otherwise difficultto-access substitution pattern. Apparently, the presence of the adjacent ferrocenyl group confers a specific reactivity on the functionalized carbon chain manifested in the easy aerobic oxidation reaction in the dry state when adsorbed on silica gel, which deserves further attention. The extension of this methodology to other relevant metallocenes as well as follow-up research on the synthetic utility of the reported funtionalized metallocene derivatives are currently under way in our group.

\section{ASSOCIATED CONTENT}

\section{Supporting Information}

Experimental procedures and spectral and analytical data for all new compounds (PDF). X-ray crystallographic data for compounds $\mathbf{3 f}$ and $\mathbf{5 b}(\mathrm{CIF})$. This material is available free of charge via the Internet at http://pubs.acs.org.

\section{AUTHOR INFORMATION}

\section{Corresponding Author}

*E-mail: lalg@uniovi.es

\section{Notes}

The authors declare no competing financial interests.

\section{ACKNOWLEDGMENT}

We are grateful to the Ministerio de Economía y Competitividad of Spain (MINECO) (Grant CTQ2010-20517-C02-01). G. L. thanks the MINECO and European Union (Fondo Social Europeo) for a predoctoral grant. We thank Prof. J. M. González for interesting discussions. We are also grateful to Dr J. Perles (SIdI, Universidad Autónoma, Madrid) and Dr N. de los Santos (Departamento de Química Física y Analítica, Universidad de Oviedo) for their assistance in the collection of the X-ray data and the electrochemical measurements, respectively.

\section{REFERENCES}

(1) (a) Kealy, T. J.; Pauson, P. L. Nature 1951, 168, 1039; (b) Miller, S A.; Tebboth, J. A.; Tremaine, J. F. Chem. Soc. 1952, 632.

(2) Selected revisions: (a) Braga, S. S.; Silva, A. M. S. Organometallics, 2013, 32, 5626; (b) Phillips, E. S. Ferrocenes: Compounds, Properties and Applications, Nova Science Publishers, Hauppauge, 2011; (c) Chiral Ferrocenes in Asymmetric Catalysis, (Eds.: Dai, L.-X.; Hou, X.- 
L.), Wiley-VCH, Weinheim, 2009; (d) Ferrocenes: Ligands, Materials and Biomolecules (Ed.: Štěpnička, P.) Wiley: Chichester, U.K., 2008; (e) Arrayás, R. G.; Adrio, J.; Carretero, J. C. Angew. Chem. Int. Ed. 2006, 45, 7674; (f) Ferrocenes, (Eds.: Togni, A.; Hayashi, T.), VCH, Weinheim, 1995; (g) Van Staveren, D. R.; Metzler-Nolte, N. Chem. Rev. 2004, 104, 5931.

(3) For a selection of recent contributions on metal-catalyzed functionalization of ferrocene derivatives via $\mathrm{C}-\mathrm{H}$ bond activation, see: (a) Gao, D.-W.; Shi, Y.-C.; Gu, Q.; Zhao, Z.-L.; You, S.-L. J. Am. Chem. Soc. 2014, 136, 86; (b) Deng, R.; Huang, Y.; Ma, X.; Li, G.; Zhu, R.; Wang, B.; Kang, Y.-B. J. Am. Chem. Soc. 2014, 136, 4472; (c) Gao, D.-W.; Yin, Q.; Gu, Q.; You, S.-L. J. Am. Chem. Soc. 2014, 136, 4841; (d) Piotrowicz, M.; Zakrzewski, J. Organometallics, 2013, 32, 5709; (e) Pi, C.; Li, Y.; Cui, X.; Zhang, H.; Han, Y.; Wu, Y. Chem. Sci. 2013, 4, 2675; (f) Sing, K. S.; Dixneuf, P. H. Organometallics 2012, 31, 7320; (g) Takebayashi, S.; Shizuno, T.; Otani, T.; Shibata, T. Beilstein J. Org. Chem. 2012, 8, 1844.

(4) For a seminal contribution on the Friedel-Crafts reactivity of ferrocene, see: Woodward, R. B.; Rosenblum, M.; Whiting, M. C. J. Am. Chem. Soc. 1952, 74, 3458. For a selection of recent contributions on the synthesis of ferrocenyl derivatives by Friedel-Crafts acylation, see: (a) Anjo, C.; Figueiredo, J. A.; Ismael, M. I.; Cabrita, I.; Fernandes, A. C. J. Organomet. Chem. 2014, 760, 19; (b) Plazuk, D.; Zakrzewski, J. J. Organomet. Chem. 2009, 694, 1802; (c) Plazuk, D.; Zakrzewski, J. J. Org. Chem. 2002, 67, 8672 .

(5) Herberhold, M.; Ayazi, A.; Milius, W.; Wrackmeyer, B. J. Organomet. Chem. 2002, 656, 71.

(6) For selected examples of Friedel-Crafts alkylation of ferrocene, see: (a) Neuse, E. W.; Trifan, D. S. J. Am. Chem. Soc. 1962, 84, 1850; (b) Leigh, T. J. Chem. Soc. 1964, 3294; (c) Plazuk, Vessières, D. A.; Le Bideau, F.; Jaouen, G.; Zakrzewski, J. Tetrahedron Lett. 2004, 45, 5425; (d) Toullec, P.; Ricard, L.; Mathey, F. Organometallics 2003, 22, 1340; (e) Plazuk, D.; Zakrzewski, J. J. Organomet. Chem. 2006, 691, 287; (f) Ahn, S.; Song, Y.-S.; Yoo, B. R.; Yang, I. N. Organometallics 2000, 19 , 2777; (g) Grevels, F.-W.; Kuran, A.; Özkar, S.; Zora, M. J. Organomet. Chem. 1999, 587, 122

(7) For selected revisions on the synthetic applications of $\alpha$-diazo carbonyl derivatives, see: (a) Doyle, M. P. Chem. Rev. 1986, 86, 919; (b) Davies, H. M. L.; Beckwith, R. E. J. Chem. Rev. 2003, 103, 2861; (c) Zhang, Z.; Wang, J. Tetrahedron 2008, 64, 6577; (d) Davies, H. M. L.; Manning, J. R. Nature 2008, 451, 417; (e) Doyle, M. P.; Duffy, R.; Ratnikov; Zhou, L. Chem. Rev. 2010, 110, 704

(8) For a selection of reviews on gold-catalysis, see the recent special issue of Accounts of Chemical Research devoted to this specific topic: Acc. Chem. Res. 2014, 47, 729-978.

(9) Fructos, M. R.; Belderrain, T. R.; de Fremont, P.; Scott, N. M.; Nolan, S. P.; Díaz-Requejo, M. M.; Pérez, P. J. Angew. Chem. Int. Ed. Engl. $\mathbf{2 0 0 5}, 44,5284$.

(10) For a selection of gold-catalyzed transformations of simple $\alpha$ diazo carbonyl compounds, see: (a) Fructos, M. R.; de Frémont, P.; Nolan S. P.; Díaz-Requejo, M. M.; Pérez, P. J. Organometallics, 2006, 25, 2237; (b) Li, Z.; Ding, X.; He, C. J. Org. Chem. 2006, 71, 5876; (c) Ricard, L.; Gagosz, F. Organometallics, 2007, 26, 4704; (d) Flores, J. A.; Dias, H. V. R. Inorg. Chem. 2008, 47, 4448; (e) Fructos, M. R.; Díaz-Requejo, M. M.; Pérez, P. J. Chem. Commun. 2009, 5153; (f) Prieto, A.; Fructos, M. R.; Díaz-Requejo, M. M.; Pérez, P. J.; Pérez-Galán, P.; Delpont, N.; Echavarren, A. M. Tetrahedron, 2009, 65, 1790; (g) Corma, A.; Iglesias, M. Llabrés i Xamena, F. X.; Sánchez, F. Chem. Eur. J. 2010, 16, 9789; (h) Rivilla, I.; Gómez-Emeterio, P.; Fructos, M. R.; Díaz-Requejo, M. M.; Pérez, P. J. Organometallics, 2011, 30, 2855; (i) Pérez, P. J.; DíazRequejo, M. M.; Rivilla, I. Beilstein J. Org. Chem. 2011, 7, 653; (j) Delgado-Rebollo, M.; Beltrán, A.; Prieto, A.; Díaz-Requejo, M. M.; Echavarren, A. M.; Pérez, P. J. Eur. J. Inorg. Chem. 2012, 1380; (k) Briones, J. F.; Davies, H. M. L. J. Am. Chem. Soc. 2012, 134, 11916; (1) Yu, Z.; Ma, B.; Chen. M.; Wu, H.-H.; Liu. L.; Zhang, J. J. Am. Chem. Soc. 2014, 136 , 6904; (m) Xi, Y.; Su, Y.; Yu, Z.; Dong, B.; McClain, E. J.; Lan, Y.; Shi, X. Angew. Chem. Int. Ed. Engl. DOI: 10.1002/anie.201404946.

(11) (a) Briones, J. F.; Davies, H. M. L. J. Am. Chem. Soc. 2013, 135 13314; (b) Pagar, V. V.; Jadhav, A. M.; Liu, R.-S. J. Org. Chem. 2013, 78 , 5711; (c) Jadhav, A. M.; Pagar, V. V.; Liu, R.-S. Angew. Chem. Int. Ed. Engl. 2012, 51, 11809; (d) Pagar, V. V.; Jadhav, A. M.; Liu, R.-S. J. Am. Chem. Soc. 2011, 133, 20728.

(12) (a) Barluenga, J.; Lonzi, G.; Tomás, M.; López, L. A. Chem. Eur. J. 2013, 19, 1573; (b) Lonzi, G.; López, L. A. Adv. Synth. Catal. 2013, $355,1948$.
(13) For some interesting contributions on the actual nature (goldstabilized carbenes $v s$ allyl gold carbocations) of alkenylgold carbenoids, see: (a) Hashmi, A. S. K. Angew. Chem. Int. Ed. 2010, 49, 5232; (b) Seidel, G.; Mynott, R.; Fürstner, A. Angew. Chem. Int. Ed. 2009, 48, 2510; (c) Hashmi, A. S. K. Angew. Chem. Int. Ed. 2008, 47, 6754; (d) Benitez, D.; Shapiro, N. D.; Tkatchouk, E.; Wang, Y.; Goddard III, W. A.; Toste, F. D. Nat. Chem. 2009, 1, 482; (e) Dateer, R. B.; Pati, K.; Liu, R.-S Chem. Commun. 2012, 48, 7200; (f) Hansmann, M. M.; Rominger, F.; Hashmi, A. S. K. Chem. Sci. 2013, 4, 1552; (g) López-Carrillo, V.; Huguet, N.; Mosquera, A.; Echavarren, A. M. Chem. Eur. J. 2011, 17, 10972.

(14) Analogous vinylogous reactivity of metal carbenes derived from vinyldiazo compounds has been reported: (a) C. Qin, C.; Davies, H. M. L. J. Am. Chem. Soc. 2013, 135, 14516; (b) Valette, D.; Lian, Y.; Haydek, J. P.; Hardcastle, K. I.; Davies, H. M. L. Angew. Chem. Int. Ed. 2012, 51, 8636; (c) Morton, D.; Dick, A. R.; Ghosh, D.; Davies, H. M. L. Chem. Commun. 2012, 48, 5838; (d) Lian, Y.; Davies, H. M. L. Org. Lett. 2012 14, 1934; (e) Hansen, J. H.; Davies, H. M. L. Chem. Sci. 2011, 2, 457; (f) Lian, Y.; Davies, H. M. L. Org. Lett. 2010, 12, 924; (g) Barluenga, J.; Lonzi, G.; Riesgo, L.; López, L. A.; Tomás, M. J. Am. Chem. Soc. 2010, 132, 13200; (h) Sevryugina, Y.; Weaver, B.; Hansen, J.; Thompson, J.; Davies, H. M. L.; Petrukhina, M. A. Organometallics 2008, 27, 1750; (i) Davies, H. M. L.; Hu, B.; Saikali, E.; Bruzinski, P. R. J. Org. Chem. 1994, 59, 4535; (j) Davies, H. M. L.; Saikali, E.; Young, W. B. J. Org. Chem. 1991, 56, 5696; (k) Davies, H. M. L.; Saikali, E.; Clark, T. J.; Chee, E. H. Tetrahedron Lett. 1990, 31, 6299.

(15) For an intramolecular insertion of carbenoids into $\mathrm{Cp}-\mathrm{H}$ bonds of ferrocenes, see: Siegel, S.; Schmalz, H.-G. Angew. Chem. Int. Ed. Engl. 1997, 36, 2456

(16) Control reactions revealed that the gold(I) catalyst is required for the reaction, since no reaction took place in its absence. On the other hand, use of $\operatorname{IPrAuNTf}_{2}(5 \mathrm{~mol} \%)$ gave a slightly lower yield of the product (44 $\%)$.

(17) For the synthesis and applications of allylferrocene, see: (a) Wedeking, K.; Mu, Z.; Kehr, G.; Cano Sierra, J.; Mück Lichtenfeld, C.; Grimme, S.; Erker, G.; Fröhlich, R.; Chi, L.; Wang, W.; Zhong, D.; Fuchs, H. Chem. Eur. J. 2006, 12, 1618; (b) Chen, W.; Chen, S.; Ding, F.; Wang, H.; Brown, L. E.; Konopelski, J. P. J. Am. Chem. Soc. 2008, 130, 12156 (c) Chen, W.; Brown, L. E.; Konopelski, J. P.; Chen, S. Chem. Phys. Lett. 2009, 471, 283.

(18) For an interesting discussion on the mechanism for the electrophilic substitution in ferrocenes, see: Cunningan Jr., A. F. J. Am. ChemSoc. 1991, 113, 4864

(19) (a) E. A. Hill, J. H. Richards, J. Am. Chem. Soc. 1961, 83, 3840; (b) E. O. Fischer, M. von Foerster, C. G. Kreiter, K. Schwarzhans, J. Organomet. Chem. 1967, 7, 113.

(20) The low yield obtained in this reaction could be ascribed to the difficulties to remove the ruthenocene excess (three chromatographic columns were required to obtain analytically pure ruthenocene $\mathbf{5 a}$ ). In fact, the ${ }^{1} \mathrm{H}-\mathrm{NMR}$ of the crude reaction revealed that no byproducts were formed.

(21) The preparation of acyl- from alkyl-ferrocenes by manganese dioxide oxidation has been reported: Rinehart Jr., K. L.; Ellis, A. F.; Michejda, C. J.; Kittle, P. A. J. Am. Chem. Soc. 1960, 82, 4112

(22) The chemistry of metallocenes adsorbed on silica gel remains almost unexplored. For recent solid-state NMR studies on the behavior of adsorbed metallocenes on silica gel, see: (a) Cluff, K. J.; Bhuvanesh, Blümel, J. Organometallics 2014, 33, 2671; (b) Cluff, K. J.; Schnellbach, M.; Hilliard, C. R.; Blümel, J. J. Organomet. Chem. 2013, 744, 119.

(23) For selected examples of iron-catalyzed aerobic oxidations, see: (a) Gonzalez-de-Castro, A.; Robertson, C. M.; Xiao, J. J. Am. Chem. Soc. 2014, 136, 8350; (b) Ratnikov, M. O.; Xu, X.; Doyle, M. P. J. Am. Chem. Soc. 2013, 135, 9475; (c) Rosa, J. N.; Reddy, R. S.; Candeiras, N. R.; Cal, P. M. S. D.; Gois, P. M. P. Org. Lett. 2010, 12, 2686; (d) Egami, H.; Katsuki, T. J. Am. Chem. Soc. 2009, 131, 6082.

(24) Although a full mechanistic understanding of this dry state aerobic oxidation reaction will require further experimentation, the in situ formation of a ferrocenium ion by oxigen could be a likely process. In this regard, it has been reported that ferrocene adsorbed on silica gel tends to oxidize in air and form ferricinium ion: Sato, H. Hyperfine Interact. 1990 57,2089 . On the other hand, under otherwise identical conditions the ruthenium derivative 5a did not afford noticeable amounts of the corresponding oxidation analogue. This outcome would be consistent with the general assumption that ruthenocenes are more difficult to oxidize than ferrocenes and would support the participation of ferrocenium ions in the 
aerobic oxidation process reported for compounds 3a-c. For the oxidation behaviour of ruthenocene derivatives, see: (a) Hill, M. G.; Lamana, W. M.; Mann, K. R. Inorg. Chem. 1991, 30, 4687; (b) Trupia, S.; Nafady, A.; Geiger, W. E. Inorg. Chem. 2003, 42, 5480.

(25) For instance, we found that heating a solution of $\mathbf{7 a}$ in chloroform at $60{ }^{\circ} \mathrm{C}$ for $2 \mathrm{~h}$ afforded quantitatively ethyl 3-ferrocenyl- $1 \mathrm{H}$-pyrazole-5carboxylate. For a related approach to pyrazole derivatives, see: Padwa, A.; Kulkarni, Y. S.; Zhang, Z. J. Org. Chem. 1990, 55, 4144. 


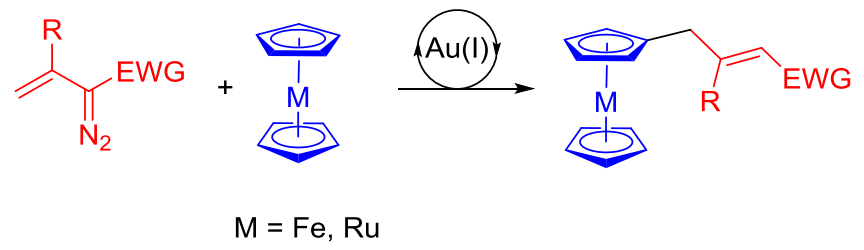

6 